\title{
La agenda social \\ latinoamericana del año 2000
}

\section{Rolando Franco \\ Director de la División \\ de Desarrollo Social, CEPAL \\ rfranco@eclac.cl \\ Pedro Sáinz \\ Director de la División \\ de Estadística y Proyecciones \\ Económicas, CEPAL \\ psainz@eclac.cl}

Terminada la década de los noventa, el bajo crecimiento económico, su vulnerabilidad ante la inestabilidad financiera internacional y los escasos avances en materia de equidad, obligan a reflexionar respecto de la agenda social futura. En ella seguirá teniendo un papel importante la lucha por la superación de la pobreza y la indigencia, condicionada en buena parte por la capacidad de la transformación económica y su dinamismo para crear puestos de trabajo en gran cantidad y de mayor calidad en términos de productividad e ingresos. A la vez, por la pesada herencia de rezagos sociales, es imprescindible que los programas sociales hagan uso eficiente de sus recursos, y para precaverse ante posibles crisis, hay que implementar redes de protección para los períodos recesivos. Dichos programas deberán asignar gran importancia a la creación de capital humano, cuidando de mejorar la mala distribución actual de la educación entre estratos sociales que constituye uno de los símbolos de los rezagos sociales latinoamericanos. Pero la educación por sí sola no basta para superar la falta de equidad, mejorar la distribución del ingreso y generar una movilidad social que permita que los hijos superen las oportunidades de bienestar material y de status social alcanzados por sus padres. La transformación económica debiera aprovechar los mayores niveles educativos creando más puestos de trabajo de mayor productividad, para lo cual hay que elevar los actuales coeficientes de inversión y la captación y difusión del progreso técnico. Una mejor combinación de trabajo, capital y progreso técnico sentará las bases de sociedades más inclusivas e igualitarias. 


\section{I}

\section{Introducción}

La vulnerabilidad de la mayoría de los países de la región frente a la inestabilidad financiera internacional, el reducido crecimiento económico, los escasos progresos en equidad y la insatisfacción que se detecta en la opinión pública, han modificado las coordenadas del debate económico y social vigente en la región, poniendo en tela de juicio algunos de los principios de las modalidades de desarrollo predominantes.

Por un lado, se postula la conveniencia de introducir cambios en la arquitectura del sistema financiero internacional (CEPAL, 1998), que tiendan a favorecer una estabilidad sostenible y a facilitar la toma de decisiones oportunas para prevenir y manejar las crisis (CEPAL, 1999a).

En la discusión internacional se expresa asimismo una fuerte preocupación por la equidad, ${ }^{1}$ aun cuando también se insta a mantener la disciplina macroeconómica (Camdessus, 1996). Se afirma que "El desarrollo es algo más que el ajuste. [Hasta ahora nos] hemos centrado excesivamente en lo económico, sin comprender bien los aspectos sociales, políticos, ambientales y culturales de la sociedad". Habría que ir entonces, se predica, "más allá de la estabilización financiera" y "abordar los problemas del crecimiento con equidad en el largo plazo, [que son la] base de la prosperidad y el progreso humano" (Wolfenson, 1998).

Por otro lado, en Europa ha surgido la discusión sobre la desigualdad "tolerable" en esas sociedades y las alternativas viables para desarrollar (o mantener) la protección de los vulnerables (Giddens, 1998). En ese contexto, ha logrado gran difusión, por lo menos mediática, el planteo de perseguir estos objetivos mediante una "tercera vía" entre las opciones tradicionales. ${ }^{2}$

\footnotetext{
${ }^{1}$ Se reclaman buenas políticas sociales, porque sin ellas la globalización y la democracia perderían legitimidad. Se recomiendan redes de protección social, la reforma agraria, fomentar la igualdad de oportunidades, y reducir las inequidades extremas en la distribución del ingreso a través de transferencias justas de ingresos desde los sectores más ricos a los más necesitados, desde los que gozan de buena salud hacia los enfermos, y desde los que tienen empleo a los que sufren de falta del mismo (Camdessus, 1996, p. 35).
}

En América Latina, entretanto, se ha perdido el optimismo de comienzos de los años noventa. Las sucesivas crisis condujeron a un crecimiento económico inferior al de otras épocas. Recuérdese que, a comienzos de los años setenta, el producto regional se incrementaba en torno al 6\% anual; hacia el final de esa década se redujo a $1.5 \%$ y cayó a 0 con la crisis de los ochenta. En la primera mitad de los noventa tuvo una recuperación esperanzadora, que alcanzó el 3\%, y llegó a su máximo en 1997 (5.3\%), para volver a caer en 1998 a 2.5\%; en 1999 el crecimiento fue negativo en la mayor parte de América del Sur, y se recuperó débilmente en 2000. También preocupa en la región que dicho crecimiento lento no genere ocupaciones de buena calidad en la cantidad necesaria para emplear a quienes ingresan a la fuerza de trabajo, especialmente jóvenes y mujeres. Esto se ha traducido en muestras de malestar de la opinión pública, desinterés en algunos casos por la actividad política y críticas al funcionamiento de los partidos políticos y del gobierno.

Ante el legado de los años noventa que se ha descrito, conviene reflexionar sobre cuáles son los temas que se encuentran incluidos en la agenda social de América Latina, y que marcarán los años iniciales del nuevo siglo.

\footnotetext{
${ }^{2}$ Los planteos son diversos. Un amplio grupo de líderes políticos mundiales parece coincidir con los partidarios de la tercera vía, que buscan combinar los aportes socialdemócratas del período denominado los "treinta gloriosos", combinándolo con las que se reconocen como ventajas del mercado. Empero, hay socialdemócratas reacios a esos cambios, al mismo tiempo que ciertos analistas para los que "la idea de la socialdemocracia carece [actualmente] de sentido, ya que corresponde al acceso al poder del sindicalismo, hoy en retroceso en todas partes", pero que creen que el nuevo "social-liberalismo" implica una alianza de centroderecha entre el Estado y las fuerzas económicas, por lo cual plantean una alternativa "dos y medio" en la que el Estado otorgue mayor peso a las presiones sociales (Touraine, 1998). Otros sectores parecen también motivados a renovar perspectivas, como sucede en Estados Unidos, con la tesis del "conservadurismo compasivo" (Olasky, 2000), adoptada por uno de los candidatos presidenciales (uno de los cuales prologó el libro mencionado anteriormente), y en la región, el intento de construir un "centro reformista". Cabe destacar asimismo ciertas coincidencias que superan las tradiciones políticas (Blair y Aznar, 2000).
} 


\section{II}

\section{La situación social actual}

\section{Pobreza e indigencia}

Según las mediciones efectuadas por la CEPAL, la pobreza disminuyó en América Latina, de $41 \%$ a 36\%, entre 1990 y 1997, recuperando así un nivel cercano al previo a la crisis de la deuda. La indigencia tuvo una evolución similar: pasó de $18 \%$ a $15 \%$ en el mismo período (CEPAL, 1999b). La crisis de 1998-1999 elevó la proporción de pobres en algunos países y atenuó la tendencia favorable que se venía observando en otros. El decenio se cerró con cerca de $38 \%$ de los hogares por debajo de la línea de pobreza y $16 \%$ en indigencia (Ocampo, coord., 2000).

La reducción que tuvo lugar en los inicios de los años noventa permitió estabilizar la cantidad de individuos pobres, mientras que el impacto de la crisis posterior volvió a elevarlo a cerca de 220 millones de personas. También subió el número de indigentes de 93.4 millones a casi 100 millones (Ocampo, coord., 2000).

Cabe extraer dos conclusiones de lo acaecido en la región en estos años. Puede afirmarse que el crecimiento económico tiene un impacto positivo en la reducción de la pobreza, aunque la intensidad de esa reducción depende del perfil de ese crecimiento. También es evidente el impacto regresivo que tienen los episodios recesivos sobre la reducción de la pobreza: un año de recesión lleva a perder entre la mitad y todo lo ganado durante cuatro o cinco años de crecimiento.

\section{Empleo y desocupación}

Hacia fines de los años noventa, junto con desacelerarse el crecimiento, se elevaron las tasas de desempleo abierto y los porcentajes de trabajo asalariado no permanente, así como el número de trabajadores sin contrato de trabajo y sin seguridad social (Ocampo, coord., 2000, pp. 49-53 y 95-102).

La tasa media regional de desempleo abierto, en 1999, fue la más alta de la década $(8.7 \%)$, pese a que bajó la tasa de participación laboral (de $58.5 \%$ a $57.9 \%$ ). Sin embargo, conviene distinguir dos situaciones: mientras México y algunos países centroamericanos y caribeños mostraron un apreciable dinamismo económico y una disminución del desempleo, este último aumentó en los países sudamericanos que enfren- taron problemas de estancamiento. El fenómeno fue especialmente notable en Chile, donde el incremento de la desocupación pasó de $6.4 \%$ en 1996 a $9.8 \%$ en 1999 (Ocampo, coord., 2000, p. 95), para seguir creciendo en 2000 hasta $10.6 \%$. Igual propensión mostró Argentina, aunque con una intensidad mucho menor, dado que frente a una caída de $3 \%$ en el producto, la desocupación sólo aumentó de $12.9 \%$ a $14.3 \%$.

También hubo cambios significativos en la organización del trabajo, que se caracterizaron por el aumento de la precariedad. Se acentuó la desregulación laboral, mediante la reducción de los costos de la mano de obra, las contrataciones de corta duración (temporal, estacional o a tiempo parcial), la ampliación de las causales de término de contrato, la reducción de las indemnizaciones por despido y del derecho de huelga, con lo que se buscó mantener o incrementar la competitividad de la economía a nivel internacional.

En esa línea se aprecia un incremento de la ocupación no permanente, aunque con gran heterogeneidad, que fluctuó entre $9.5 \%$ (Costa Rica) y $45.1 \%$ (Ecuador) en 1997, y con ascensos extremos en Colombia, donde pasó de 6.6\% en 1980 a $20.0 \%$ en 1997. Este tipo de empleo temporal es más común en las microempresas, y entre los menores de 30 años, las mujeres y las personas de bajo nivel educativo (Martínez y Tokman, citados en Ocampo, coord., CEPAL, 2000, p. 99).

Se incrementó asimismo el número y la proporción de quienes estaban ocupados pero no tenían contrato de trabajo. En 1996, la proporción de asalariados en esta situación fluctuaba entre $65 \%$ y $22 \%$, según los países. Obviamente, la precariedad estaba vinculada con menores remuneraciones y mayor vulnerabilidad y pobreza.

Una importante proporción de trabajadores no contaba con protección de la seguridad social y de la salud. Las diferencias nacionales son notables: van de más de $60 \%$ sin protección en Bolivia y Paraguay a una protección casi total en Uruguay (CEPAL, 2000, p. 101).

\section{Distribución del ingreso}

Durante los años ochenta, los gobiernos centraron su preocupación en el crecimiento económico y el alivio de la pobreza. Para ello se suponía que bastaba con 
recuperar los equilibrios macroeconómicos, acabar con la inflación, retirar al Estado de ciertas áreas y ampliar espacios para el sector privado. Muchos de quienes propiciaban estas políticas pensaban que, en el largo plazo, el chorreo (trickle-down) terminaría con la pobreza. La distribución del ingreso no era un objetivo, porque se creía que podría afectar tanto el crecimiento económico como la posibilidad de reducir la pobreza que derivaba de él.

Hoy, la distribución del ingreso ha vuelto a ganar status político, tanto porque el crecimiento económico no parece haber conducido en general a una mejor distribución, como porque el debate económico ha vuelto a considerar la distribución, relacionándola con tres temas relevantes.

Una primera línea de análisis retoma la tesis de que una distribución del ingreso más igualitaria promueve el crecimiento económico, en oposición al argumento de que, por lo menos en las primeras fases del proceso de desarrollo, el ingreso debe concentrarse en ciertos grupos que tienen capacidad de ahorrar e invertir. Se han planteado dudas, incluso, sobre si los grupos de mayores ingresos de la región tienen esa capacidad, por la tendencia al consumo que suelen mostrar (ILPES, 1999, pp. 15-19).

También se han relacionado distribución del ingreso y pobreza. El argumento, de carácter mecánico, sostiene que hoy existiría una pobreza "innecesaria" en América Latina (Berry, 1997), por cuanto si se hubiera mantenido la distribución del ingreso de comienzos de los años ochenta, el aumento de la pobreza derivado de la crisis habría sido 50\% inferior (Londoño y Szekely, 1997).

Finalmente, se sostiene que la reducción de las desigualdades incrementa la estabilidad de los sistemas políticos democráticos, mientras que la concentración crea mayores riesgos, derivados de la reacción de los grupos perdedores que buscan mejorar su desmedrada posición.

La distribución del ingreso en América Latina en los años noventa puede analizarse a través de los siguientes indicadores:

i) el porcentaje de hogares que obtiene un ingreso inferior al ingreso promedio de la sociedad muestra que, entre 1970 y 1990 , la cifra pasó de $67 \%$ a $75 \%$, manteniéndose en ese nivel a lo largo de los años noventa. Esto permite afirmar que la evolución del ingreso promedio no representa bien lo que le está sucediendo a tres cuartas partes de la población latinoamericana;

ii) el coeficiente de Gini indica que, en el período 1990-1997, aumentó la desigualdad en siete países y se redujo en sólo cuatro (CEPAL, 1999b). Como suele recordarse, América Latina es la región del mundo que tiene la peor distribución del ingreso. Sin embargo, constituye un conjunto heterogéneo de naciones entre las cuales existen grandes diferencias, ubicándose en los polos extremos Brasil y Uruguay (CEPAL, 1998, pp. 216-217, cuadro 23);

iii) la razón entre los ingresos obtenidos por el $10 \%$ más rico de la población y por el $40 \%$ de menores ingresos entre 1990 y 1997 creció en siete países y se redujo en cuatro (CEPAL, 1999b, pp. 64 y 66).

Cabe concluir, entonces, que la modalidad de crecimiento económico vigente en la región durante los últimos años, en el mejor de los casos, no ha contribuido a disminuir las desigualdades que tradicionalmente la han caracterizado. Empero, "los problemas no son un producto del modelo actual de desarrollo, ya que también caracterizaron al anterior y [a] los que le antecedieron. Reflejan, de esta manera, y no debe ocultarse, problemas fundamentales de la estructura económica y social" (Ocampo, 2000, p. 125).

Esa vocación por la desigualdad parece no ser peculiar de América Latina. Se encuentra incluso en el mundo desarrollado, aunque con otros niveles de concentración. En Estados Unidos, por ejemplo, varios analistas han hecho notar que las tecnologías de la información incrementan las oportunidades de empleo e ingresos para los "analistas simbólicos", como se designa a aquellos trabajadores de alta calificación dedicados a producir bienes inmateriales que hacen uso intensivo de conocimiento (Reich, 1993). A la inversa, los obreros de la línea de montaje se ven afectados por la creciente exigencia de calificaciones informáticas, y porque las empresas trasladan los procesos rutinarios de producción a otros países (Thurow, 1992). Asimismo, en la Comunidad Europea se han percibido notables diferencias entre "las retribuciones de los sectores acomodados de la población [que] están aumentando de manera significativa" y las posibilidades de ocuparse, las características del tipo de empleo que consiguen y las remuneraciones que obtienen las personas del 40\% inferior (Dahrendorf, 1996, p. 44).

Esas características del sistema económico mundial, que derivan en parte de la incorporación de nuevas tecnologías, se unen en América Latina a factores específicos que explican la concentración de la distribución del ingreso y que no facilitan su modificación en el corto plazo.

La CEPAL (1998) ha identificado cuatro especialmente relevantes:

i) Patrimonio: La distribución del patrimonio en América Latina es aun más concentrada que la del in- 
greso total. En promedio, el ingreso patrimonial se sitúa en el percentil 85 (CEPAL, 1998, gráfico 4), lo que indica que $85 \%$ de la población latinoamericana tiene un acceso al patrimonio menor que el nivel medio de la sociedad.

ii) Demografía: Los hogares de menores ingresos tienen más miembros, en promedio cinco o más personas, que los hogares de mayores ingresos.

iii) Ocupación: La densidad ocupacional, vale decir, la cantidad de ocupados en relación con el total de miembros del hogar, tiene especial importancia para explicar lo que sucede con la distribución del ingreso. En algunos países, el estrato alto dobla a los estratos bajos en este indicador. Dada la importancia que tiene el ingreso laboral en el ingreso total del hogar, esta diferencia explica buena parte de la alta concentración distributiva. La distancia que separa a quienes se ubican en el primer decil de la distribución del ingreso y a los que están en el $40 \%$ inferior aumenta por la ya anotada disparidad creciente de las remuneraciones entre ocupaciones modernas y empleos de baja productividad.

iv) Educación: La distribución del ingreso está condicionada también por la educación. Si bien ella ha aumentado en los últimos 25 a 30 años, al punto que las nuevas generaciones tienen en promedio tres años de estudio más que sus padres, existe una alta concentración del capital educativo.

\section{Gasto social: ¿ventana de oportunidades desaprovechada?}

Luego de la reducción del gasto público social que se dio en la mayoría de los países en la década de 1980, se produjo un significativo aumento de ese gasto durante los años noventa. Entre 1990-1991 y 1996-1997 creció $38 \%$ para el conjunto de la región, duplicando así el crecimiento del producto por habitante y haciendo que tres cuartas partes de los países superaran su nivel máximo histórico. Esa tendencia pareció continuarse hacia fines de la década, aunque al respecto cabe esperar los resultados que presentará la CEPAL en su Panorama Social de América Latina, 2000-2001.

Sin embargo, esta "ventana de oportunidades" —que acompaña al "bono demográfico"3 de que disfruta la re-

\footnotetext{
${ }^{3}$ La expresión "bono demográfico" busca destacar la ventaja para la región latinoamericana que deriva de un crecimiento de la población que se ha hecho más pausado y, por consiguiente, ha elevado la proporción de población adulta dentro del total, lo que hace que en teoría disminuya la tasa de dependencia (CEPAL/CELADE, 1996).
}

gión-, no ha sido aprovechada a cabalidad. Conviene insistir en que gastar mucho no significa necesariamente gastar bien, siendo una de las tareas pendientes el incrementar la eficiencia, la eficacia y el impacto ${ }^{4}$ de este tipo de recursos, hecho de especial importancia para una región que dedica al gasto público porcentajes del PIB claramente inferiores a los que destinan a ese fin los países desarrollados.

Debe advertirse, además, que resulta cada vez menor el margen de que disponen los gobiernos para seguir elevando su gasto público social a un ritmo más rápido que el de su crecimiento económico. El mantenimiento de los actuales niveles de recursos públicos para los programas sociales es un desafío inmediato.

\section{Insatisfacción en la opinión pública}

En los comienzos de los años noventa, la preocupación principal de los latinoamericanos se centraba en los procesos inflacionarios que corroían sus ingresos. Los gobiernos que tuvieron éxito con la estabilización recibieron respaldo electoral (Mora y Araujo, 1992). Sólo algunos sectores, en especial los ocupados en el sector público, reaccionaron frente a las pérdidas relativas de salarios y beneficios (CEPAL, 1995). El resto de la ciudadanía apostó al futuro, con la esperanza de que también recibirían su parte de los frutos del crecimiento.

Hoy, en cambio, predomina la incertidumbre. La situación económica y social descrita ha contribuido a diluir esperanzas y ha hecho que aflore, en muchos casos, el cansancio con el ajuste permanente. Encuestas de opinión realizadas en 16 países señalan que aproximadamente $67 \%$ de los entrevistados considera que la distribución de la riqueza es injusta y $61 \%$ sostiene que su país no se está desarrollando (CEPAL, 1998).

Obviamente, tales opiniones están fuertemente basadas en la experiencia personal de quien las emite. No piensan igual los que participan de los sectores emergentes o quienes están saliendo de la pobreza, que los miembros de sectores medios hoy empobrecidos,

\footnotetext{
${ }^{4}$ La eficiencia mide la relación que existe entre costos y productos (bienes o servicios) entregados por el proyecto. El objetivo del análisis de eficiencia es encontrar la alternativa que minimiza los costos por unidad de producto. La eficacia da cuenta del grado en que se han alcanzado las metas de producción del proyecto, en un período de tiempo, con independencia de los costos en que se haya incurrido.

El impacto expresa la magnitud del beneficio recibido por la población objetivo, según los fines del proyecto: por ejemplo, el porcentaje de reducción de la desnutrición de grado 1 y 2 en el grupo meta, que se alcanzó por un proyecto orientado a ese fin (véase Cohen y Franco, 1992).
} 
que pueden comparar su nivel de vida actual con el que disfrutaron en el pasado.

Existen, por lo demás, diferencias generacionales. La generación actual siente que tiene menores oportunidades, tanto respecto de la generación que la antecedió como de la que la sucederá (Latinobarómetro, 2000, p. 11).

Es muy común que los jóvenes demuestren insatisfacción por las dificultades que afrontan para encontrar un empleo acorde con sus aspiraciones. Conviene hacer notar que esta percepción parece tener una fuerte base material, sobre todo en la evolución del mercado de trabajo y en las dificultades para el funcionamiento adecuado de las microempresas y pequeñas empresas.

Llama la atención la similitud entre el porcentaje de jóvenes insatisfechos (entre $49 \%$ y 63\%, según encuestas realizadas en siete países) y el de quienes no han logrado una educación que les asegure cierta movilidad social mediante una integración adecuada al mercado de trabajo ${ }^{5}$ (entre un tercio y la mitad). Podría sostenerse que estos jóvenes con capitales educativos insuficientes toman conciencia tempranamente de cuán predeterminada y limitada es la secuencia de oportunidades de bienestar de que disfrutarán a lo largo de su vida (Gerstenfeld, 1998).

En Chile -donde las reformas económicas han madurado más que en otros lados y se han alcanzado elevados niveles de crecimiento-, se aprecia una creciente preocupación por la desigualdad, que ha tendido a desplazar a la pobreza concebida como carencia de recursos. "Este cambio implica que la población presta particular atención al diferente ritmo con que los beneficios del progreso económico alcanzan a diferentes sectores de nuestra sociedad" (Manzi y Catalán,
1998, p. 555). Los opinantes de sectores bajos y medios consideran que los niveles de pobreza y desigualdad vigentes no se condicen con el crecimiento alcanzado. Piensan que esa incongruencia deriva de la propia dinámica del sistema y de la política de los actores sociales con poder de decisión, a los que critican su falta de sensibilidad. Reclaman, asimismo, un papel más activo del Estado (ibid., p. 532).

La percepción de la desigualdad y de la falta de oportunidades lleva a que los ciudadanos pierdan progresivamente confianza en los políticos y en las instituciones, al tiempo que se alejan de los partidos (Manzi y Catalán, 1998). Se produce un distanciamiento de la actividad política, a la que ya no se ve como instancia en la cual es posible defender los intereses grupales y contribuir a crear una sociedad cuyas distancias sociales tengan una magnitud razonable. Sin embargo, existe apoyo a la democracia como el mejor sistema de gobierno, aunque no hay igual satisfacción con su funcionamiento, debido a las altas expectativas cifradas en la capacidad del sistema democrático para dar solución a los problemas. Sólo el 37\% de los latinoamericanos está satisfecho con el desempeño de la democracia (Latinobarómetro, 2000, p. 6).

Debe reconocerse, sin embargo, que un proceso de desarrollo implica desencadenar demandas. Incluso cuando hay crecimiento económico y avances sociales en la satisfacción de necesidades básicas (agua potable, electricidad, caminos rurales), las encuestas de opinión no necesariamente mostrarán satisfacción. La teoría de Maslow (1954), según la cual la satisfacción de ciertas necesidades primarias implica el inmediato surgimiento de otras nuevas fuertemente sentidas, puede explicar parcialmente el descontento frente al surgimiento de nuevas expectativas y aspiraciones.

\section{III}

\section{Los temas sociales emergentes}

Ante un panorama como el descrito, un elemento fundamental de la agenda latinoamericana en la próxima década será la construcción de sociedades más igualitarias, lo que pasa por la incorporación de altos por-

\footnotetext{
${ }^{5}$ Esto es, lograr una educación de duración superior a la de sus padres, descontada la devaluación, y alcanzar el umbral mínimo para incorporarse adecuadamente al mercado de trabajo.
}

centajes de la población a la sociedad de consumo y la existencia de canales que promuevan la movilidad social.

\section{Integración a la sociedad de consumo}

En América Latina, la mayoría de los hogares no logra ingresos suficientes para acceder a un nivel míni- 
mo del consumo de masas. Este es una dimensión no sólo del bienestar material, sino de status y de integración, crecientemente valorados por la sociedad. Pese a ello es común que se insista en denunciar lo que denominan "consumismo", que sería una desviación de ciertos patrones culturales, la que derivaría del efecto de demostración por el cual se adoptan modas "propias" de otros estratos sociales y de otros países.

En general, sólo dos a tres de cada 10 hogares urbanos registran actualmente un ingreso per cápita suficiente para integrarse a la sociedad de consumo de dimensiones y calidades latinoamericanas. ${ }^{6}$ En las áreas rurales, la situación es aun menos favorable. Como excepción, en Uruguay alrededor de la mitad de los hogares tiene esa posibilidad; en otros países, un tercio. Una hipótesis optimista sostiene que en 2005 sólo Argentina y Chile se podrían incorporar al grupo de países latinoamericanos con más de la mitad de sus hogares integrados al consumo (Gerstenfeld, 1998).

Probablemente, son los miembros de estos hogares no pobres urbanos con ingresos insuficientes para integrarse plenamente al consumo los que más influyen en la sensación de frustración que detectan las encuestas (Gerstenfeld, 1998).

El crecimiento económico sostenido es, sin duda, el instrumento por el cual podrá lograrse que las grandes masas puedan incorporarse al consumo.

\section{Movilidad social}

Una sociedad abierta, moderna, preocupada por la equidad, debería caracterizarse por la fluidez de su movilidad social. Una manera de asegurar el buen desempeño de los roles sociales es que existan las posibilidades y los incentivos para acceder a las posiciones mejor remuneradas o de mayor status. En las sociedades tradicionales, en cambio, los roles se asignan básicamente por principios de adscripción que reservan esas posiciones por nacimiento.

En las primeras fases de desarrollo tiene lugar un tipo de movilidad "estructural", por la cual se crean aceleradamente nuevas posiciones de mejor nivel, a las cuales se accede cualquiera sea la preparación para

\footnotetext{
${ }^{6}$ Para integrarse a la sociedad de consumo se requiere un ingreso per cápita del hogar superior a tres líneas de pobreza. En ese punto, la distribución muestra un claro salto en el nivel de gasto. Recuérdese que una línea de pobreza es, justamente, el nivel de la pobreza; percibir un ingreso de hasta dos líneas de pobreza muestra vulnerabilidad y riesgo de sufrir esa situación en alguna etapa de la vida.
}

ejercer esas funciones. En fases más avanzadas, la movilidad se torna "circular": la generación de nuevas posiciones es menor y el cambio tiene que darse por rotación, esto es, por el abandono de alguno de los ocupantes de la posición más elevada (por retiro, muerte o desempleo), y el que asciende requiere credenciales adecuadas para su desempeño (Pastore y Silva, 2000, p. 5).

Los estudios muestran que, en la región, sólo tuvieron movilidad educacional dos de cada cuatro jóvenes urbanos y uno de cada cuatro rurales. En consecuencia, cabe concluir que la probabilidad de movilidad social prácticamente no ha cambiado desde 1980 (CEPAL, 1998a). La alteración de ese patrón está ligada fuertemente al sistema educativo.

Conviene destacar aquí que la sociedad meritocrática, donde las posiciones son desempeñadas por poseer ciertas capacidades, puede sumir en la exclusión y la pobreza a aquellos que no las posean. Esto justifica el argumento de que es preciso incorporar un elemento de solidaridad, que permita compensar esas carencias.

\section{Hacia sociedades más igualitarias}

Suele hacerse mucho hincapié en los aspectos económicos de la desigualdad. La experiencia latinoamericana muestra que incluso en aquellos países donde se ha logrado cumplir con la recomendación de mantener tasas de crecimiento de $6 \%$ anual, la distribución no mejora y tampoco hay diferencias respecto a la satisfacción de la opinión pública con lo que está sucediendo. Se destaca por ello "la necesidad de poner especial atención a las políticas económicas y sociales que tienen directa incidencia en aspectos de carácter distributivo, especialmente en aquellas áreas donde la sensibilidad por la desigualdad se manifiesta con mayor fuerza (educación, vivienda, y salud)" (Manzi y Catalán, 1998, p. 555). Asimismo, la ya mencionada nueva reflexión intelectual sobre la distribución del ingreso analiza relaciones que parecen mostrar que incluso para crecer es preferible una mayor igualdad en esta dimensión.

Siendo muy importante ese tema, conviene recalcar que la preocupación por construir sociedades más igualitarias va más allá de lo económico y lo relacionado con el bienestar material. Importan otras formas de igualdad sin las cuales no existe una buena sociedad.

Esos avances en la satisfacción de necesidades básicas generan costos monetarios que deben ser 
enfrentados por los beneficiarios, lo que resulta difícil cuando no se ha elevado la productividad de esos sectores atrasados y no han surgido nuevas opciones laborales que les permitan sustentar los avances logrados.

Pero la sociedad igualitaria va más allá del consenso sobre los elementos económicos cruciales. En primer lugar, porque es un requisito previo para el buen funcionamiento del propio mercado. Así sucede con la igualdad ante la ley, que si bien aparece expresada en las constituciones latinoamericanas, dista mucho de estar vigente en la práctica. Las reformas a la justicia constituyen el reconocimiento de las carencias existentes en la región. También es un requisito ineludible la igualdad de oportunidades, entendida como la superación de la desventaja que deriva para algunas personas de la existencia de ciertas barreras o constricciones o de la imposibilidad de acceso a ciertos medios. Igualar oportunidades implica eliminar las conexiones que existen entre las posibilidades de bienestar y ciertas características personales que no pueden ser modificadas o sólo son difícilmente alterables (sexo, raza), o que derivan del nacimiento en una familia con determinados atributos (nivel socioeconómico, casta, etc.).

En definitiva, incluso cuando se privilegia la libertad, corresponde asegurar una igualdad de libertades, esto es, "preocuparse igualmente, al nivel que sea, por todas las personas implicadas" (Sen, 1999, p. 7).

También corresponde promover la igualdad de posibilidades de expresión del pensamiento. Existen sin duda, en cualquier país, múltiples perspectivas sobre cómo organizar la sociedad. Y debe reconocerse a las personas, a las comunidades y a los grupos su derecho a expresar sus preferencias y a organizarse para sostenerlas en el debate democrático.

Muchos de esos principios son fundamentales para un adecuado funcionamiento de la democracia. El principio de "un hombre, un voto" tiene que ser respetado para que la democracia funcione. Se requiere igualdad ciudadana. Si bien se habla del "mercado político", no puede aceptarse que el mercado (económico) determine las decisiones políticas. Se necesita cautelar "que quienes pesan y valen distinto en el mercado a partir de lo que tienen, adquieran peso y valor equivalente a la hora de ejercer como ciudadanos sus derechos cívicos y políticos, sociales y laborales, valóricos e ideológicos" (Hardy, 2000).

La igualdad de derechos ciudadanos lleva a que las diferencias personales no se transformen en privilegios de algunos y exclusiones de otros.

En el campo de la sociedad y la cultura se necesita también igualdad en la diversidad, esto es, que los individuos, las comunidades y los grupos de diferente tipo tengan la posibilidad de desarrollar su propia visión de las diferentes dimensiones del comportamiento humano y poder así desenvolver sus "hechos diferenciales"; esto lleva al pluralismo cultural.

Pero el crecimiento también depende de las políticas sociales en cuanto éstas forman el capital humano que se movilizará para poder desempeñar correctamente los puestos de trabajo que requiere el funcionamiento del aparato económico. Asimismo, las políticas sociales contribuyen a crear condiciones políticas que son básicas para generar la estabilidad necesaria para la inversión y la realización de los proyectos productivos.

\section{Responsabilidad de las políticas públicas}

Sin duda, uno de los instrumentos claves para enfrentar la agenda social finisecular serán las políticas públicas. Una buena política económica tiene efectos sociales positivos. Genera condiciones para crear empleos y buenos salarios. Incluso cuando sólo se crean ocupaciones con productividad e ingresos bajos, como ha sucedido predominantemente en estos años, ello permite que un número mayor de miembros de los hogares pobres consiga ocuparse, con lo que aumenta la densidad ocupacional de los hogares y, consecuentemente, su ingreso per cápita. El crecimiento económico facilita, además, la expansión del gasto público, con su potencial de mejorar en equidad y disminuir la pobreza en el corto y largo plazo.

Sin embargo, conviene tener presente que "la sensibilidad del crecimiento regional a los ciclos financieros internacionales sigue siendo tan marcada como siempre, pese a la creciente sofisticación del manejo macroeconómico" (Ocampo, 2000, p. 122). Esto obliga a tratar de reducir el impacto de dichos ciclos sobre la población en general y en especial sobre los más desprotegidos. Asimismo, la creciente segmentación del mercado del trabajo exige políticas orientadas a evitar que los precios relativos afecten la contratación laboral; que aseguren una capacitación permanente de la mano de obra y preparen a los trabajadores para operar con nuevas tecnologías, y que perfeccionen la legislación laboral y establezcan seguros de desempleo que brinden protección a los trabajadores en coyunturas recesivas y readecuaciones productivas. Dado que los sectores de baja productividad están compuestos por empresas pequeñas y microempresas, las que ocupan más de la mitad de los trabajadores latinoamericanos, hay que fomentar en ellas la absorción de nueva tecnología, para lo que se les debe garantizar el 
acceso al crédito y a los mercados, y apoyarlas en lo que toca a información, desarrollo de productos y canales de comercialización y gestión empresarial.

Asimismo, las políticas de vivienda popular y equipamiento comunitario son vitales para mejorar las condiciones de vida de las personas, elevar la calidad de la salud y crear el entorno propicio para que los escolares aprovechen la educación, al mismo tiempo que contribuyen a mejorar la distribución del patrimonio. Donde la población rural es aún significativa, es preciso facilitar el acceso a los mercados a productores de regiones apartadas mediante la realización de obras de infraestructura y el acceso a la tierra y al agua.

En cuanto a las políticas sociales, es claro que no pueden asumir solas el objetivo de la equidad. El desarrollo social no es de su responsabilidad exclusiva: comparte tal responsabilidad con la política económica. Las políticas sociales influyen directa e indirectamente en la disminución de la pobreza y el mejoramiento de las condiciones de vida, a través de sus tres funciones básicas: inversión en capital humano, compensación social e integración o cohesión social.

\section{a) Inversión en capital humano: la educación}

Cuando el principal factor productivo es el conocimiento hay una base sólida para justificar la conveniencia de una mayor equidad. Ya no es necesario recurrir solamente a argumentos éticos, filantrópicos o de solidaridad. Los países no podrán ser competitivos si no tienen una fuerza de trabajo adecuadamente formada y capacitada, que pueda acceder al progreso técnico e incorporarlo a su rutina de trabajo. Es posible, entonces, concebir la competitividad y la equidad como objetivos que pueden perseguirse simultáneamente y retroalimentarse. De esta manera, desde el punto de vista agregado, la política social que se orienta a invertir en capital humano se convierte en un prerrequisito del crecimiento económico. Otro tanto sucede con la necesidad de habilitar a la población en términos de salud para que pueda ejercer sus funciones productivas a un nivel adecuado.

La educación también es clave para los individuos. Sin embargo, es preciso reconocer que ella (especialmente la de calidad) es un bien que se hereda. Hay una transmisión intergeneracional de las oportunidades de bienestar (CEPAL, 1998) que vincula al hogar de origen con los años de educación, el tipo de ocupación y el nivel de bienestar que sus nuevos miembros podrán alcanzar a lo largo de su vida.

En primer lugar, el hogar de origen tiene un papel fundamental en el aprovechamiento escolar. Hay varias características de ese hogar que influyen: i) el nivel socioeconómico; ii) el clima educacional, definido como la cantidad de años de estudio que tienen los adultos del hogar; iii) las condiciones habitacionales (si hay hacinamiento o no), y iv) la organización familiar (que puede ser monoparental, o con ambos padres presentes, influyendo también el tipo de unión).

Tempranamente, entonces, se decide el futuro de las nuevas generaciones, diferenciando entre los excluidos (aquellos cuya educación es insuficiente como para tener la posibilidad de ocupar empleos bien remunerados que los liberen de la pobreza) y los integrados. Los excluidos no alcanzarán niveles de vida adecuados, ni estarán en condiciones de aportar a la competitividad, por cuanto carecerán de conocimientos y de la flexibilidad necesaria para incorporar el progreso técnico a sus formas de producción.

En otro eslabón de la cadena, el capital educativo es clave en las oportunidades ocupacionales al llegar a la vida activa, debido a dos fenómenos fuertemente relacionados y que es necesario considerar en el diseño de políticas: devaluación educativa y umbral educativo.

La devaluación educativa es la pérdida de importancia de ciertos niveles académicos a medida que se generaliza su obtención; en definitiva, da cuenta de la necesidad de cursar cada vez más años de educación formal para acceder a la misma ocupación o para obtener un salario similar al que se lograba en la generación precedente. ${ }^{7}$ La experiencia muestra que cuanto menor sea el nivel educativo, mayor es la devaluación.

El umbral educativo, a su vez, es el número de años que se debe cursar como mínimo, en cada momento determinado, para obtener una ocupación que asegure una alta probabilidad (90\%) de evitar la pobreza a lo largo del ciclo de vida. Dicho umbral hoy, en América Latina, se sitúa en muchos casos en los 12 años de educación formal (CEPAL, 1999b) y sólo lo alcanza un tercio de los jóvenes en las zonas urbanas y un décimo en las rurales.

Finalmente, la ocupación a la que se acceda se encadena con las oportunidades de bienestar, como se ha destacado en el Panorama social de América Latina. Quienes tienen menos de ocho años de estudio sólo podrán acceder a ocupaciones que les proporcionarán ingresos que se sitúan en torno a dos y media líneas

\footnotetext{
${ }^{7}$ Este tema fue profundamente analizado hace ya mucho tiempo por Aldo E. Solari, y se encuentra presente en estudios de la CEPAL. Recientemente ha cobrado expresión en la prensa: véase $L a$ Tercera (2000).
} 
de pobreza, que resultan insuficientes para un bienestar mínimo. En el otro extremo, quienes tienen 12 ó más años de estudio se desempeñarán como técnicos, gerentes o propietarios y, en esas ocupaciones, obtendrán ingresos superiores a las cuatro líneas de pobreza. Quienes se encuentren en una posición intermedia (9 a 11 años de estudio) trabajarán como vendedores en general o en profesiones similares, recibiendo un ingreso que, en ciertas etapas de su ciclo de vida - cuando hayan constituido una familia y sus hijos lleguen a la adolescencia-, puede no proporcionarles un nivel de bienestar adecuado (CEPAL, 1998).

Desde el punto de vista societal, el costo de los recursos humanos sin capacitación, que no resultan eficientes en sistemas de producción competitivos, puede definirse como "el potencial de crecimiento en la dotación de capital humano, que no se concreta como consecuencia de los déficit educativos existentes" (Cohen, 1996, p. 4).

Por lo mismo, si bien tienen gran importancia las políticas de reforma educativa que buscan reducir la repetición y la deserción y mejorar la calidad de la educación, no son suficientes por sí solas para superar la falta de equidad. Hay que considerar los factores extraescolares en el rendimiento educativo, y compensar las diferencias ligadas al hogar de origen de los alumnos, como única manera de evitar que el sistema educativo funcione como mecanismo de reproducción de diferencias preexistentes.

Conviene insistir en que mejorar la educación no basta para modificar la distribución del ingreso en los próximos 10 años. Como la rotación de personas en la fuerza de trabajo se realiza a un ritmo de $2 \%$ ó $3 \%$ anual, el perfil ocupacional del $80 \%$ de los trabajadores que estarán en funciones hacia fines de la próxima década ya está incorporado hoy al mercado laboral. Por ello, no obtendrán ventaja alguna de las mejoras en el sistema educacional, que se orientan justamente a quienes aún no se han incorporado al mercado de trabajo.

La distribución del acceso a la salud también es inequitativa, aunque cabe reconocer avances en la reducción de la mortalidad infantil y el aumento de la esperanza de vida, entre otros logros. Sin embargo, existen hoy nuevas demandas que obligarán a ampliar las políticas y a otorgar servicios más diversificados y modernos, no sólo en actividades preventivas. Los procesos de reforma llevados a cabo, en los cuales el sector privado desempeña un papel significativamente más importante que en el pasado, han dado lugar a un importante debate sobre la mejor manera de mejorar la eficiencia y responder a demandas cada vez mayores.

\section{b) Compensación social: redes de protección}

La lucha por la superación de la pobreza y la indigencia seguirá siendo central. Cobran importancia las redes de protección social, vale decir, aquellos "conjuntos de intervenciones compensatorias que incrementan el ingreso y otros activos mediante transferencias focalizadas, y que están diseñadas específicamente para sostener o aumentar el bienestar de los grupos pobres o vulnerables en períodos de transición económica" (Graham, 1994). Algunos creen incluso que pueden facilitar un respaldo popular al proceso de transición económica, siempre que exista una comunicación adecuada y se fomente la participación de los beneficiarios, fortaleciendo su capacidad de organización.

Estas redes deben ser estables, pertenecer a sistemas institucionales permanentes, tener personal especializado, mecanismos de elegibilidad, carteras de proyectos y prácticas establecidas para evaluarlos, etc. De no ser así, no podrán responder oportunamente a las necesidades de protección en momentos de crisis (Cornia, 1999).

Desde los años ochenta la protección de los pobres en las crisis se ha basado en programas de empleo de emergencia, programas contra la pobreza y fondos sociales de emergencia o de inversión social, con los que se buscó complementar a los tradicionales programas de asistencia social. Pero también cabe recurrir a medidas que les mantengan la ocupación mediante, por ejemplo, el adelanto de la inversión programada en infraestructura o la promoción de obras públicas en comunidades que hayan enfrentado desastres naturales o coyunturas económicas desfavorables (Iglesias, por publicarse). Como criterio básico de estos programas debe considerarse su operación contracíclica, expandiendo su cobertura y beneficios en los períodos de recesión. Corresponde, por ello, que se identifiquen aquellos rubros que no deben recortarse, o que necesitan ampliarse durante las crisis.

\section{c) Cohesión social}

Una sociedad integrada es aquella en la cual la población se comporta según patrones socialmente aceptados y existe un ajuste entre las metas culturales, la estructura de oportunidades para alcanzarlas y la formación de capacidades individuales para aprovechar tales oportunidades. Por cierto, siempre hay comportamientos que no se ajustan a esas pautas, que pueden inducir aumentos de la cohesión social o procesos de desintegración usualmente vinculados a fenómenos de 
exclusión, vale decir, a circunstancias en que la sociedad no pone a disposición de las personas los medios (oportunidades) adecuados para que puedan alcanzar las metas impuestas por la cultura (CEPAL, 1997, cap. III, p. 73).

La preocupación por la cohesión no implica la búsqueda de la homogeneización, por cuanto una sociedad moderna tiene que respetar el derecho a la identidad cultural propia y valorar la diversidad, junto con los aportes que derivan de la creatividad de cada grupo cultural. Así, se comparten objetivos globales y normas, y existe espacio para una amplia gama de metas particulares, tanto individuales como grupales. Esto es de especial importancia en sociedades multiétnicas y multiculturales.

A los tradicionales problemas de baja integración social que presenta la región (pobreza y otros ya vistos, discriminación étnica, segmentación social, segregación residencial), se agregan ahora nuevos fenómenos (violencia en diversas formas, inseguridad ciudadana, narcotráfico, corrupción).

\section{IV}

\section{Conclusiones}

El fin de siglo en América Latina, en el plano social, no es satisfactorio. Si bien se ha recuperado la senda del crecimiento económico, éste no tiene el ritmo necesario para mejorar los niveles de vida en toda la población. Las políticas sociales, por su parte, han recibido recursos muy importantes, que no será fácil mantener si no se asienta el crecimiento económico, y que en todo caso exigen mejoras notables en la eficiencia de su aplicación, en la eficacia para alcanzar los objetivos y en el impacto de los programas sobre la población beneficiaria.

En la agenda futura de la región estará presente la aspiración de construir sociedades más inclusivas e igualitarias, con una incorporación creciente a la sociedad de consumo y a la movilidad social, de estratos de la población hasta ahora excluidos.

Conviene insistir en la importancia de la democracia y de su calidad. Ella es un ingrediente básico para una buena sociedad. Las democracias de analfabetos no son tales democracias y, con mucha facilidad, abren camino al clientelismo y al populismo. Las sociedades de excluidos también son el caldo de cultivo
Este conjunto de situaciones debilitan o anulan los lazos de una pertenencia compartida, la aceptación de patrones de comportamiento común y el ejercicio de una ciudadanía efectiva, al mismo tiempo que refuerza particularismos excluyentes y genera desconfianza hacia el ordenamiento público.

Por lo mismo, el mejoramiento de la integración social se liga a la recomposición de canales de movilidad social adecuados a las transformaciones en curso, a la puesta en práctica de un desarrollo cuyos frutos lleguen al conjunto de la sociedad, a un ámbito público que reconozca y valore la diversidad y aliente el fortalecimiento de los actores de la sociedad civil, y a un sistema político en que se representen y negocien las demandas e intereses de todos los actores.

La incorporación de los excluidos por discriminaciones de diverso tipo (étnicas, de género y otras) es una tarea pendiente. En ella, la acción afirmativa o discriminación positiva es un medio fundamental para avanzar en la superación de las desigualdades adscritas al origen familiar, étnico y de género. ${ }^{8}$

de la violencia y la inseguridad ciudadana y terminan afectando el funcionamiento de la democracia. Deterioran asimismo las condiciones de vida no sólo de los pobres, sino también de los integrados, que pasan a vivir en bunkers, a no circular con tranquilidad por su propia ciudad y a fomentar el desarrollo de la industria de la seguridad privada.

Uno de los debates europeos actuales gira en torno a la sociedad de dos tercios, esto es, aquélla donde sólo dos de cada tres personas están integradas. Hoy, en América Latina predominan sociedades de un tercio. El desafío, entonces, es crear sociedades donde, como dice el título de un libro reciente, Todos entran (Bustelo y Minujin, 1998). Ese es el desafío de la región, que sólo será auténticamente competitiva si simultáneamente logra el desarrollo humano.

\footnotetext{
${ }^{8}$ Recurriendo, por ejemplo, a la discriminación positiva o acción afirmativa para reducir las diferencias y desigualdades, solución hoy cuestionada en algunos medios. Así, el Presidente Fernando Henrique Cardoso destaca las resistencias que existen en Brasil a un sistema de cuotas para facilitar el acceso de los negros a la educación (véase Cardoso, 1998, p. 328).
} 
Como ha sostenido Dahrendorf (1996), "Alcanzar al mismo tiempo crecimiento, cohesión y libertad puede ser difícil; puede incluso implicar la cuadratura del círculo, [esto] por supuesto no puede lograrse de manera perfecta; pero es posible que podamos acercarnos a ello".

\section{Bibliografía}

Berry, A. (1997b): The income distribution threat in Latin America, Latin American Research Review, vol. 32, $\mathrm{N}^{\circ} 2$, Albuquerque, New Mexico, University of New Mexico.

Blair, T., y J. M. Aznar (2000): El crecimiento es el objetivo esencial para Europa, El país, Madrid, 18 de junio.

Bustelo, E. y A. Minujin (1998): Todos entran, Buenos Aires, Fondo de las Naciones Unidas para la Infancia (UNICEF)/Editorial Losada.

Camdessus, M. (1996): Los nuevos pilares para una nueva solidaridad, Círculo de Montevideo, Los nuevos caminos de América Latina, Primera Reunión Plenaria, Montevideo, 5-6 de septiembre.

Cardoso, F. H. (1998): El Presidente segundo o Sociólogo, Entrevista de Fernando Henrique Cardoso a Roberto Pompeu de Toledo, São Paulo, Companhia das Letras.

CEPAL/CELADE (Comisión Económica para América Latina y el Caribe/Centro Latinoamericano de Demografía) (1996): Impacto de las tendencias demográficas sobre los sectores sociales en América Latina: contribución al diseño de políticas y programas, Serie E-CELADE, $\mathrm{N}^{\circ} 45$, Santiago de Chile.

CEPAL (1995): Panorama social de América Latina, 1995, LC/G.1886$\mathrm{P}$, Santiago de Chile.

(1997): La brecha de la equidad: América Latina, el Caribe y la cumbre social, LC/G.1954, Santiago de Chile. (1998a): Panorama social de América Latina 1997, LC/G.1892-P, Santiago de Chile.

(1999a): La crisis financiera internacional: una visión desde la CEPAL, LC/G.2040, Santiago de Chile. (1999b): Panorama Social de América Latina 1998, LC/G.2050-P, Santiago de Chile.

(2000): Panorama social de América Latina 1999-2000, LC/G.2068-P, Santiago de Chile.

Cohen, E. (1996): Presentación, Educación, eficiencia y equidad, Santiago de Chile, CEPAL/Organización de los Estados Americanos(OEA)/Ediciones SUR.

Cohen, E. y R. Franco (1992): Evaluación de proyectos sociales, México, D.F., Siglo XXI Editores.

Cornia, A. (1999): Liberalization, globalization and income distribution, Working paper, $\mathrm{N}^{\circ} 157$, Helsinki, World Institute for Development Economics Research (WIDER).

Dahrendorf, R. (1996): La cuadratura del círculo. Bienestar económico, cohesión social y libertad política, México D.F., Fondo de Cultura Económica (FCE).

Gerstenfeld, P. (1998): Oportunidades de bienestar y movilidad social en América Latina. Percepciones y realidades, Revista paraguaya de sociología, año $35, \mathrm{~N}^{\circ} 101$, Asunción, Paraguay, Centro Paraguayo de Estudios Sociológicos (CPES).

Giddens, A. (1998): El centro derecha sigue en la confusión neoliberal, El país, $\mathrm{N}^{\circ} 933$, Madrid, 22 de noviembre.

Graham, C. (1994): Safety Nets, Politics and the Poor, Washington, D.C., The Brookings Institution.
Hardy, C. (2000): Repensar la agenda progresista, Revista Rocinante, Santiago de Chile, octubre.

Iglesias, E. V. (por publicarse): La crisis, el desempleo y las redes de protección social. Explorando nuevas fronteras, en R. Franco (ed.), Sociología del Desarrollo, Políticas Sociales y Democracia, Buenos Aires, Fondo de Cultura Económica (FCE).

ILPES (Instituto Latinoamericano y del Caribe de Planificación Económica y Social) (1999): Reflexiones sobre el desarrollo y la responsabilidad del Estado, Santiago de Chile.

La Tercera (2000): Santiago de Chile, 24 de septiembre.

Latinobarómetro (2000): Informe de prensa, 1999-2000, Santiago de Chile, Corporación Latinobarómetro.

Londoño, J. L. y Szekely (1997): Persistent Poverty and Excess Inequality: Latin America, 1970-1995, Working paper series, $\mathrm{N}^{\circ}$ 357, Washington, D.C., Banco Interamericano de Desarrollo (BID).

Manzi, J. y C. Catalán (1998): Los cambios en la opinión pública, en C. Toloza y E. Lahera (eds.), Chile en los noventa, Santiago de Chile, Presidencia de la República/Dolmen Ediciones.

Maslow, H. H. (1954): Motivation and Personality, Nueva York, Harper \& Bros.

Mora, M. y M. Araujo (1992): Ensayo y error, Buenos Aires, Editorial Sudamericana.

Morley, S. (1998): La pobreza en tiempos de recuperación económica y reforma en América Latina: 1985-1995, en E. Ganuza, L. Taylor y S. Morley (eds.), Política macroeconómica y pobreza en América Latina y el Caribe, Madrid, Programa de las Naciones Unidas para el Desarrollo (PNUD)/Mundiprensa.

Ocampo, J. A. (2000): Nuestra agenda, La CEPAL en sus 50 años. Notas de un seminario conmemorativo, Libros de la CEPAL, $\mathrm{N}^{\circ} 54$, Santiago de Chile, CEPAL.

Ocampo, J. A., coord. (2000): Equidad, desarrollo y ciudadanía, LC/G.2071, Santiago de Chile, CEPAL.

Olasky, M. (2000): Compassionate conservatism, Nueva York, The Free Press.

Pastore, J. y N. do V. Silva (2000): Movilidade social no Brasil, São Paulo, Makron Books.

Reich, R. (1993): El trabajo de las naciones. Hacia el capitalismo del siglo XXI, Buenos Aires, Vergara.

Sen, A. K. (1999): Nuevo examen de la desigualdad, Madrid, Alianza Editorial.

Thurow, L. (1992): La guerra del siglo XXI, Buenos Aires, Javier Vergara Editor.

Touraine, A. (1998): 3 y 2⿺𠃊1/2, El país, No 911, Madrid, 31 de octubre.

Wolfenson, J. D. (1998): La otra crisis, discurso pronunciado ante la Junta de Gobernadores del Banco Mundial, Washington D.C., 6 de octubre. 